\title{
Explanation of Pap Smear Preventive Behavior among Women Based on Health Belief Model: A Qualitative Study
}

Afshin Bahmani

* Assistant Professor of Health Education, Dept. of public health, Faculty of health, Kurdistan, University of Medical Sciences, Sanandaj, Iran

(KUMS), Sanandaj, Iran (Correspondent author) a_bahmani59@yahoo.com

Khaled Rahmani

Assistant Professor of Epidemiology, Dept. of social determinants of health research, Kurdistan, University of Medical Sciences, Sanandaj, Iran

Farzaneh Ahmadian

BSc in Public Health, Health Network of Sarvabad , Kurdistan, University of Medical Sciences, Sanandaj, Iran

Zainab Alizadeh

BSc in Public Health, Health Network of Sarvabad, Kurdistan, University of Medical Sciences, Sanandaj, Iran

Bahieh Akhtar

BSc in Public Health, Health Network of Sarvabad , Kurdistan, University of Medical Sciences, Sanandaj, Iran

Received: 27 September 2016 Accepted: 22 February 2017 DOI: 10.18869/acadpub.ihepsaj.5.1.5

\section{ABSTRACT}

Background and objective: Cervical cancer is one of the most prevalent cancers among women. Although Pap smear test is an effective screening program, it is not conducted very frequently. This study aimed to recognize the determinants affecting women's participation in Pap smear test screening, with a qualitative approach, based on the health belief model (HBM).

Materials and methods: This was a qualitative research, based on thematic analysis, conducted in 2015. Participants were 30 rural women who participated in this study voluntarily in Sarvabad County in Kurdestan Province in Iran. Purposive sampling was used to recruit participants and sampling continued until data saturation. Semi-structured interviews were used to collect the data. Data were analyzed using thematic analysis.

Results: Based on participants' perception, more of the women believed that they were not at risk for cervical cancer; however, they perceived the severity of the disease. Some of them did not have an adequate understanding of the test benefits. They pointed to financial difficulties, fear of test result and lack of awareness are the main barriers in taking Pap smear test.

Conclusion: Several factors affect women's participation in screening and Pap smear test. These factors include the components of social, economic, cultural, attitudes, individual beliefs, lack of awareness, fear, etc. Findings of this study could help health administers and planners in designing and implementing interventional programs such as theory-based educational programs, face-toface educational classes, expert advice and speech of clergy people and influential community people to increase women's participation in Pap smear test screening program.

Keywords: Pap test, Cervical cancer, Health Belief Model (HBM), Qualitative study, thematic analysis, Sarabad County.

Paper Type: Research Article.

Citation (Vancouver): Bahmani A, Rahmani K, Ahmadian F, Alizadeh Z, Akhtar B. Explanation of Pap smear preventive behavior among women based on Health Belief Model: A qualitative study. Iran J Health Educ Health Promot. Spring 2017;5(1): 5-14. [Persian]

- Citation (APA): Bahmani A., Rahmani, K., Ahmadian, F., Alizadeh, Z., \& Akhtar, B. (Spring 2017). Explanation of Pap smear preventive behavior among women based on Health Belief Model: A qualitative study. Iranian Journal of Health Education \& Health Promotion., 5(1), 5-14. [Persian] 


\section{تبيين رفتار بِيشكَيرانه انجام آزمايش پاباسمير در زنان مبتنى بر الكَوى اعتقاد \\ بهداشتى: مطالعه كيفى}

\section{جكيده}

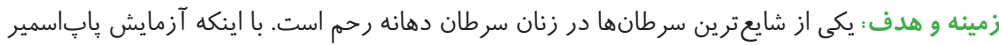

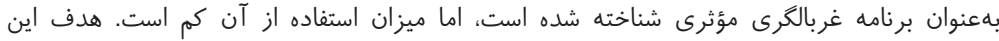

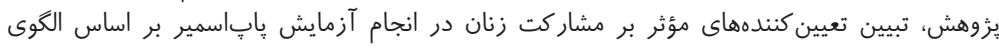

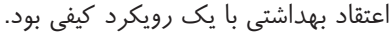

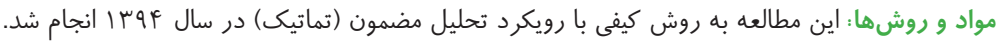

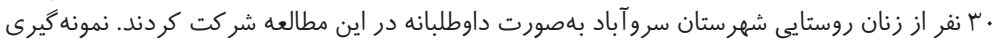

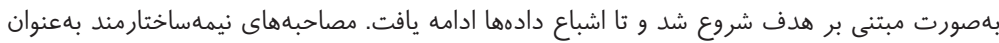

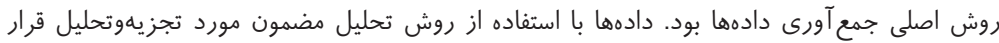

كرفتند.

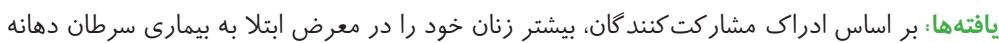

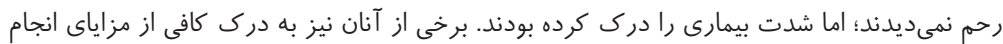

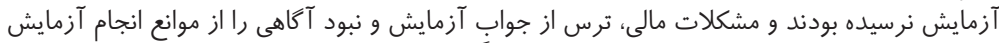

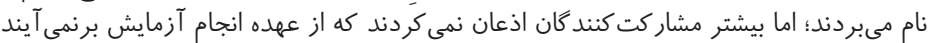

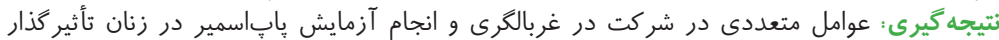

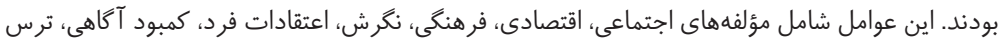

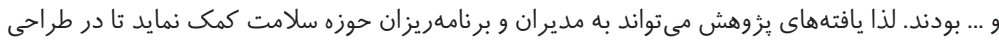

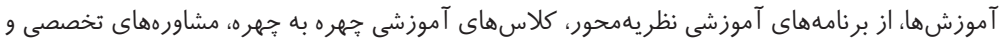

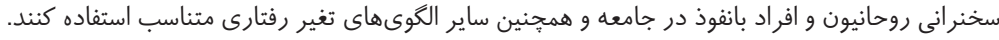

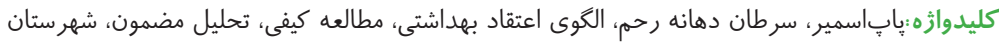

سروآباد.

نوع مقاله : مطالعه يزوهشى.

4 استناد (ونكوور): بهمنى الف، رحمانى خ، احمديان ف، عليزاده ز، اختر ب. تبيين رفتار بيشكيرانه

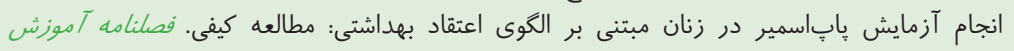

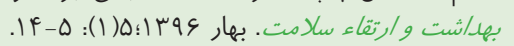

4 استناد (APA): بهمنى، افشين؛ رحمانى، خالد؛ احمديان، فرزانه؛ عليزاده، زينب؛ اختر، بهيه (. بهار

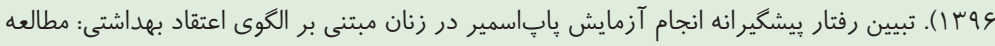

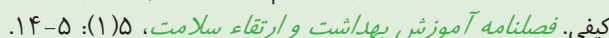

\section{a_bahmani59@yahoo.com}

خالد رحمانى الني استاديار ابيدميولوثى، مركز تحقيقات عوامل اجتماعى رئى

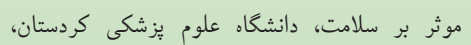

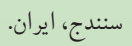
فرز زانه احمد يان اندان كارشناس بهداشت عمومى، شبكه بهداشت و درمان آبان

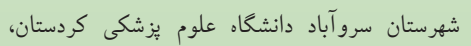

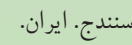

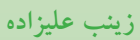
كارشناس مامايى، شبكه بهداشت و درمان شهرستان سرو آباد دانشكاء علوم يزشكى كردستان، سنتدج. ايران.

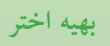

كارشناس مامايي، شبكه بهداشت و درمان شهرستان

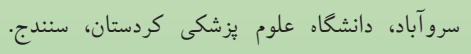

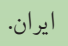

تاريخ دريافت: تاريخ:

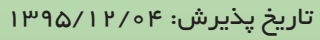




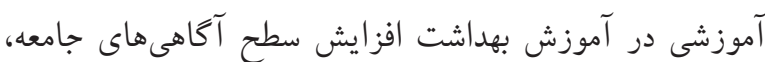

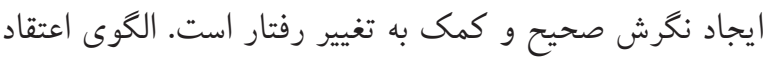
بهداشتى بهعنوان جهارجوب نظرى براى اين مطالعه بيشنهادشده

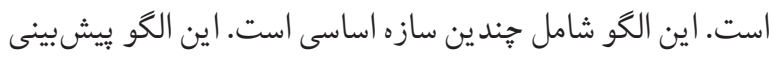

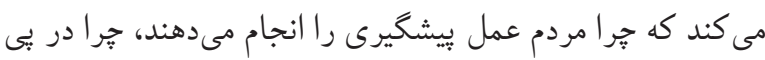
اعمال غربالكرى مىروند و جُكونه شرايط بيمارى خود را كنترل

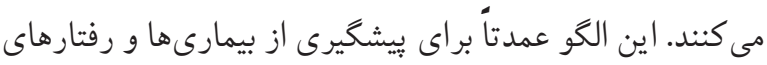

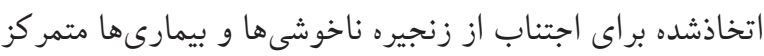
است و ازجمله الكوهاى مهم و دقيقى است كه براى ييش بينى رفتار مرتبط با بهداشت در الخوى اعتقادى معين تلاش مي كند.

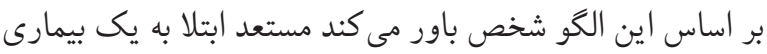

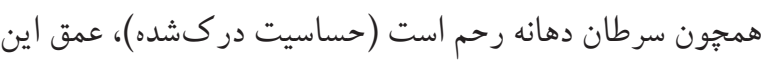

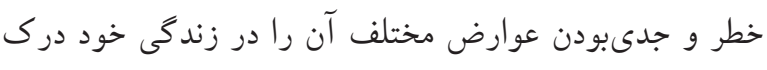
مى كند (شدت دركشده) و رفتارهاى بيشنهادشده مانند انجام

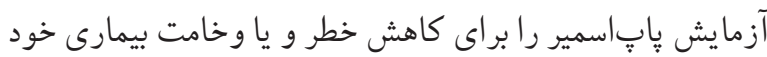

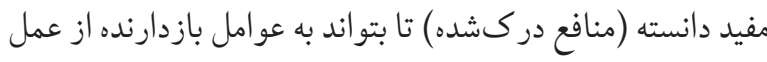

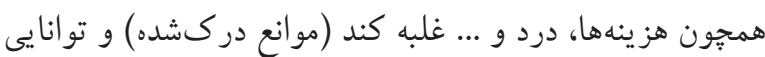

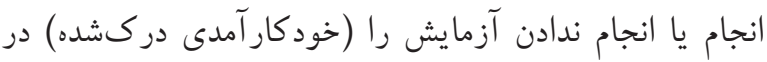

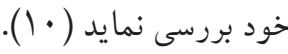
توجه به اين امر ضرورى است كه بين حقيقت و مسائل دنياى واقعى تفاوت وجود دارد. بهعبارتديگر، بين حقيقت موجود و آنجه در ذهن و ادراكات عموم مردم نسبت به سرطان

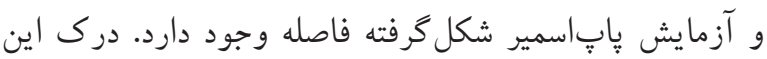

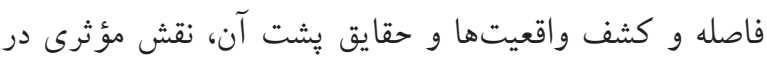
درك عوامل مؤثر بر مشاركت زنان مشاركت كننده در اين

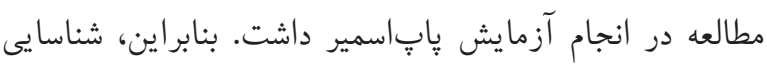
اين عوامل فراتر از توصيف كمى و معنادار بودن بين متغيرها

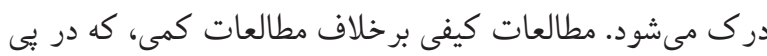

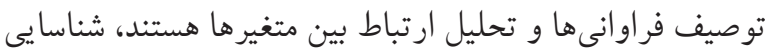
ريشهاى شكل گيرى نكرش، باور، عادات و رفتار را هدف قرئ نرار
سرطان دهانه رحم يكى از مشكلات عمده بهداشت عمومى در

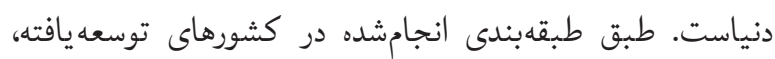
ميزان ابتلا به اين بيمارى در بين زنان در رده سوم و در كشورهاى دئي

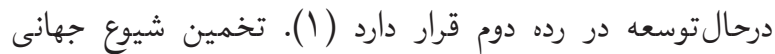

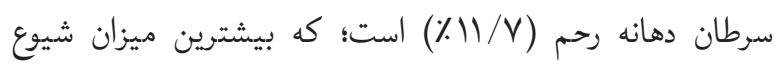

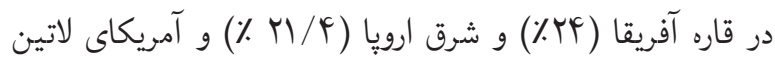

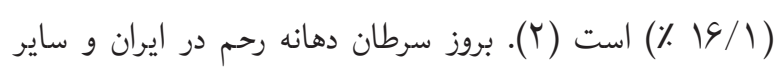
كشورهاى مسلمان در سطح پايينى قرار دارد (广). ميزان بروز

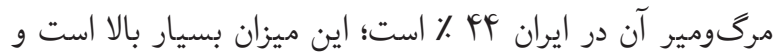

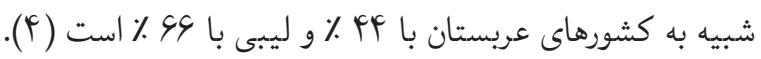

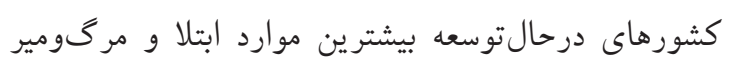
ناشى از سرطان دهانه رحم را دارند. به اين دليل كه در اين

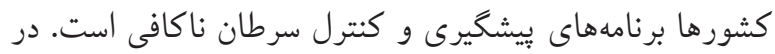

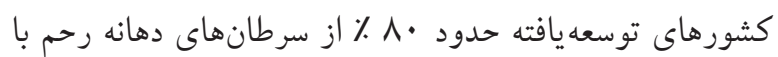
اجراى برنامهاى مؤثر بيشخيرى و درمانهاى مؤثر در مراحل اوليه سرطان كاهشيافته است (ه). رفتار بهداشتى بيشخيرانه

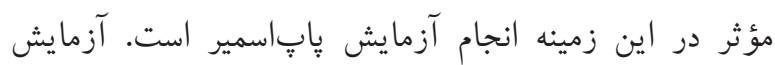

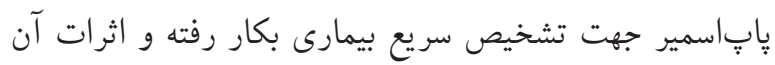

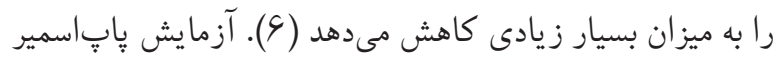

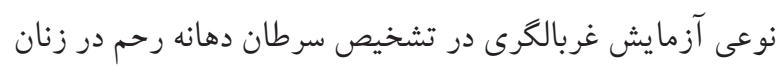
بهظاهر سالم بوده و يك رفتار بهداشتى و ارتقادهنده سلامتى سربـ محسوب مىشود. اين آزمايش هر سه سال يكبار در زنانى كه ونه

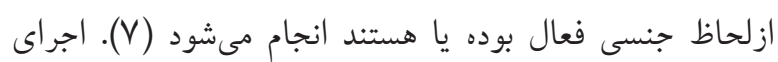

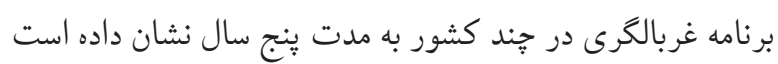

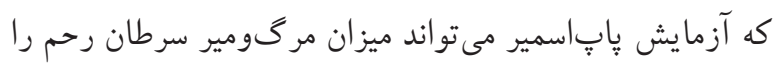

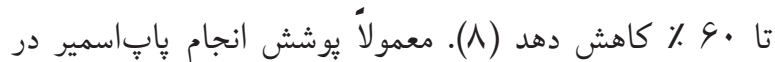

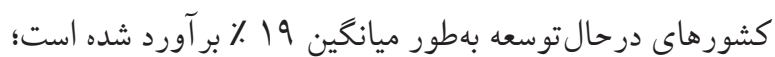

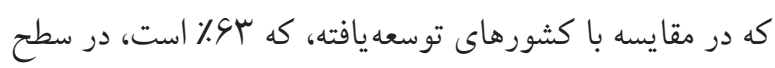
بسيار پايين ترى قرار دارد (9).

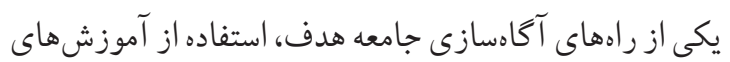


مصاحبه ساختارمند با استفاده از سؤالات باز بوده است. اين نوع

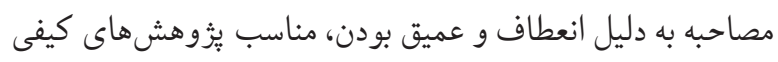

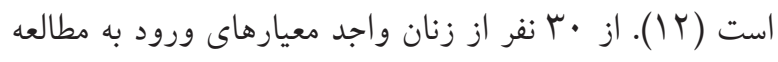

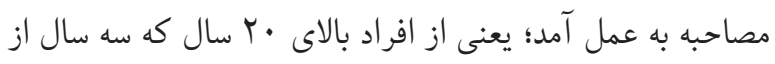

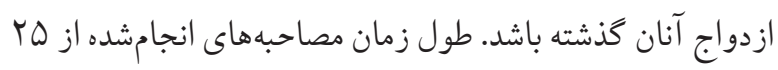

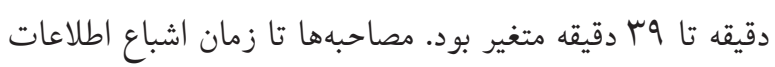

$$
\text { يعنى نفر سىام ادامه ييدا كرد. }
$$

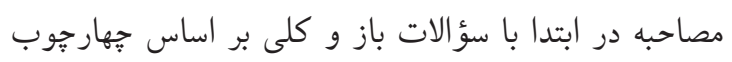

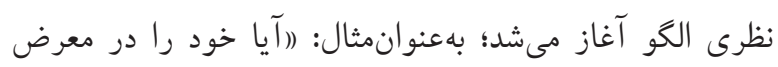

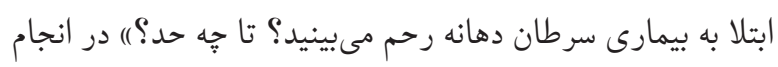

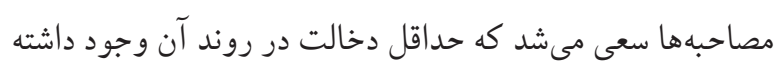
باشد. همجنين سؤالات عمقدهنده مصاحبه مثلاينكه (ابيشتر

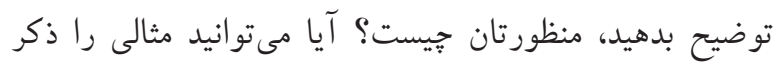

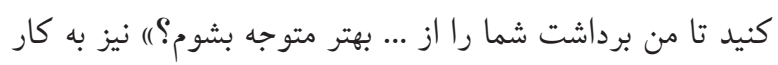

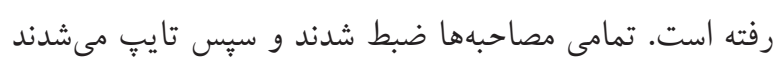

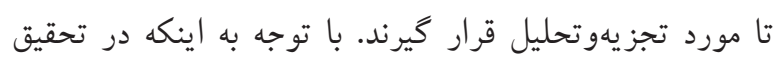

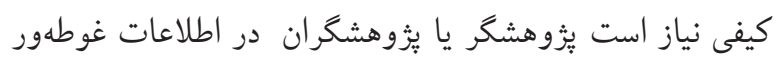

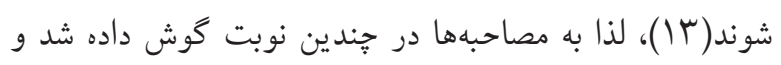

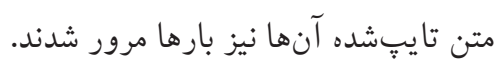

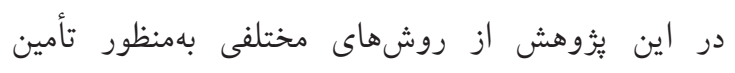

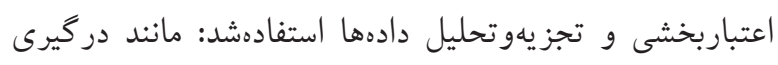
مستمر و غوطهور شدن` در اطلاعات جمع آورىشده و خواندن جندينباره دستنوشتها و روش ارزيابى عضوّ براى مقايسه بين

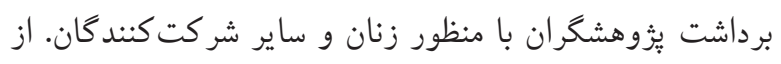

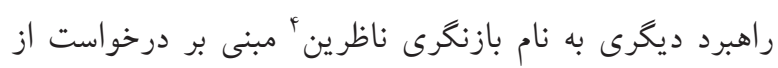

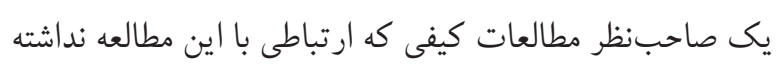
باشد استفاده شد تا تمام مراحل تحليل محتو ايى اطلاعات حاصل دئل

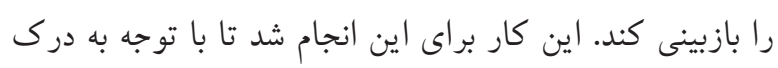

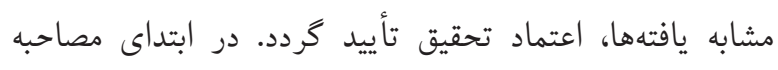

2. prolonged engagement

3. member check

4. peer debriefing
مى دهند. اخرجه مطالعات كمى به گسترش دانش حقيقى كمى

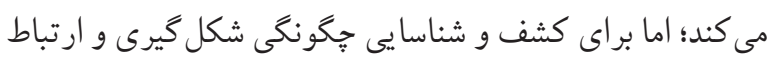

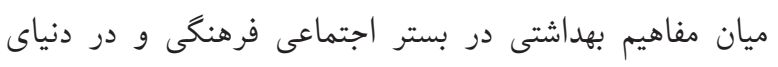

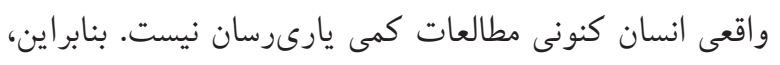

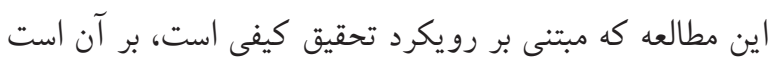

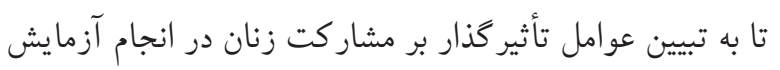
ياضٍاسمير بيردازد. مو اد و روش ها اين مطالعه يك مطالعه كيفى با روش تحليل مضون (تماتيك)

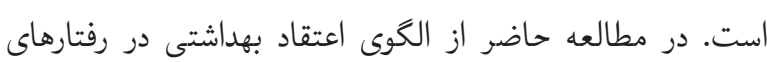
غربالكرى سرطان دهانه رحم جهت استخراج كدها استفادهد. جهار سازه حساسيت و شدت دركشده و منافع و موانع دركشده از ميان شش سازه الكو در اين مطالعه مدنظر بودند.

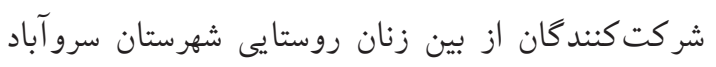

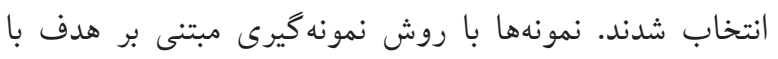

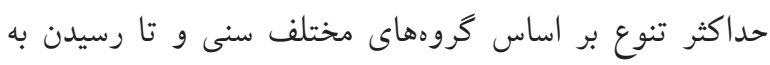

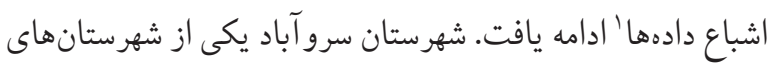

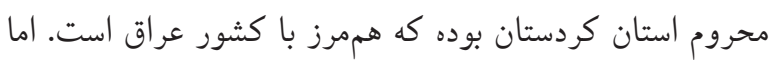

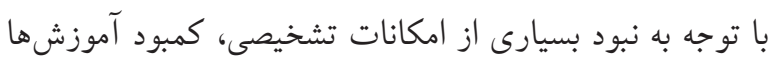

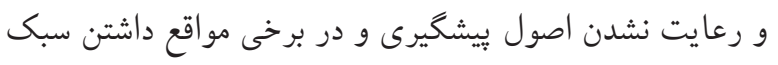

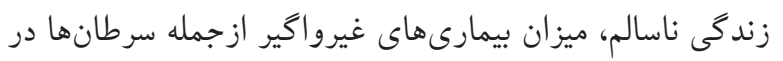

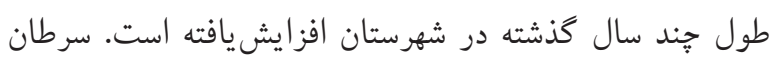

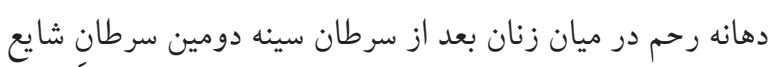

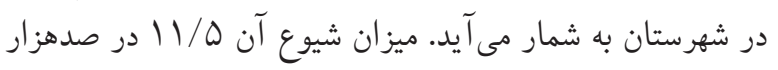

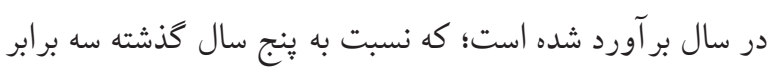

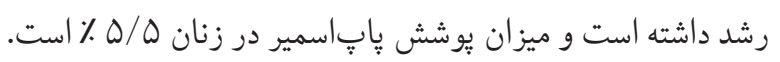

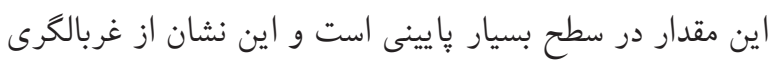
ضعيف اين بيمارى در سطح زنان شهرستان است (11). روش اصلى جمع آورى دادهها در اين مطالعه استفاده از

1. data saturation 
جدول r. طبقات اصلي و فرعي درونمايه (حساسيت دركشده)

\begin{tabular}{|c|c|c|}
\hline طبقه اصلى & طبقه فرعى & كد آزاد \\
\hline \multirow[b]{2}{*}{ باورهاى فرهنگى اشتباه } & سلامتى & رقوى و سالم بودن \\
\hline & ترس & 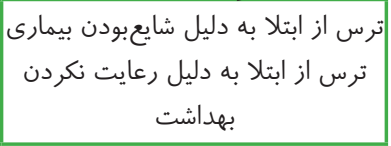 \\
\hline ارثى دانستن بيمارى & وراثت & انتقال ارثى زييمارى ارى \\
\hline باورهاى مذهبى اشتباه & قضا و قدر & سرطان نتير انسانها دست عذاب دنيوى است \\
\hline
\end{tabular}

1 - اباورهاى فرهنگ اشتباه:

((من آدم قوى و سالمى هستم و زياد به بيمارى فكر نمى كنم و احساس مى كنم آدم زياد به هر جى فكر كنه، به اون مبتلا مىشه. حالا بيمارى باشه يا هر جتيز ديخه)) (هr ساله، سواد راهنمايى و داراى دو فرزند كه تابهال آزمايش پِاٍ|سمير را انجام نداده

(امن اين احساس رو ندارم كه روزى به اين بيمارى مبتلا بشم. جون هر بار رفتم معاينه، كفتند رحم ڤاكى دارى) (Y ساله، بىسو ادو داراى دو فرزند كه تابهحال آزمايش پِإ)

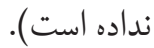
| - ارثى دانستن بيمارى:

(ا(من فكر نمى كنم هيجوقت به سرطان دهانه رحم مبتلا بشم. جون زمينه ارثى نداريم و بيشتر كسانى مبتلا مىشوند كه زمينه ارثى دارند)) (DF ساله، ديڤمه و داراى سه فرزند كه تابهحال سه

$$
\text { بار آزمايش پايّاسمير را انجام داده است). }
$$

(امن احتمال مىدم كه به اين بيمارى مبتلا بشم. جون مادربزرگ من در اثر همين سرطان فوت كرده و ميخن اين سرطان هم ارثيه و من هميشه از اين مىترسم) ( سأ ساله، دييلمه و داراى دو فرزند كه هرساله آزمايش ڤاب/اسمير را انجام داده

1 - باورهاى مذهبي اشتباه:

(امن احتمال نمىدم به بيمارى مبتلا بشم. مخه اينكه واقعاً خدا بخواد. جون تقدير آدمها دست خداست)) ( • F ساله، بىسواد و
به مشاركت كنندگان درباره هدف تحقيق، روش مصاحبه، اطميناندادن از محرمانه بودن اطلاعات و حق آنها در شركت يا خروج از مطالعه توضيح داده شد و رضايت آكاهانه از آنان كسب كرديد. زمان مصاحبه نيز با هماهنكى و خواست مصاحبه كننده تنظيم گرديد؛ يعنى به صورتى كه سبب اختلال در كارهاى روزانه آنها نشود.

إقته يس از مشخصشدن مفاهيم اوليه، كدهاى اوليه از مصاحبهها استخراج شدند. اين كدها يس از جِند بار مرور و خلاصهسازى و بر اساس تناسب و تشابه طبقهبندى شدند و در زيرطبقات درونمايههاى اصلى بر اساس جهارجّوب الكوى اعتقاد بهداشتى از قبل تعيينشده قرار كرفتند. اين درونمايههاى مبتنى بر الخو بود: حساسيت دركشده، شدت دركشده، منافع دركشده و موانع دركشده. خصوصيات فردى شركت كنندكان در اين مطالعه در جدول ا نشان داده شده است.

جدول ا. خصوصيات فردى زنان شركت كننده در مطالعه كيفى

\begin{tabular}{|c|c|}
\hline $94 / 94$ & درصد يوشش بيمهاى افراد \\
\hline \$9/4 & درصد افراد استفادهكنده از وسيله يِيشيرى از \\
\hline 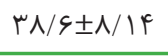 & ميانخين سنى افراد \\
\hline$r / G \cdot \pm I / F V$ & ميانظين تعداد اولاد \\
\hline$r \Lambda / \Lambda V \pm \Delta /{ }^{\prime} r$ & ميانگين شاخص توده بدنى (BMI) \\
\hline
\end{tabular}

از · م مصاحبه انجامشده •V9 كد اوليه استخراج شد؛ كه بهدقت مورد ارزيابى قرار كرفتند. سيس ع • إ كد اصلى استخراج شدند؛ كه به بr كد تقليل دادهشدند. در مرحله بعدى با بررسى كدهاى اصلى، Y Y طبقه فرعى و ها طبقه اصلى استخر اج شدند. 1. حساسيت دركشده زنان بييرامون سبرطان دهانه رحم: اكثر زنان درك كمى از خطرات ابتلا به سرطان دهانه رحم داشتند؛ كه اين درونمايه خود به جندين طبقه اصلى و فرعى تقسيم مىشوند

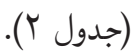


روند سلامتى خويش مىدانستند؛ كه اين درونمايه خود به جندين طبقه اصلى و فرعى تقسيم مىشوند (جدول \&).

جدول ז. طبقات اصلى و فرعى درونمايه (منافع درىشده)"

\begin{tabular}{|c|c|c|}
\hline طبقه اصلى & طبقه فرعى & كد آزاد \\
\hline \multirow[t]{2}{*}{ احساس سلامت و آسايش } & امنيت روانى & احساس سلامتى و امنيت خاطر \\
\hline & ارزش گذارى & افزاريش اميد به زنادن به خود \\
\hline تشخيص بهموقع & |درمانيذير بودن & امريد به درمان \\
\hline
\end{tabular}

ب-1 احساس سلامت و آسايش:

(انفع انجام آزمايش ڤإ)

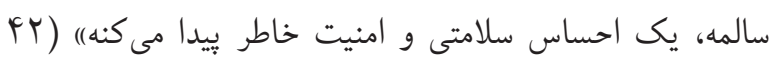
ساله، سواد ابتدايى و داراى جهار فرزند كه تابهحال دو بار آزمايش پِاب/سمير را انجام داده است).

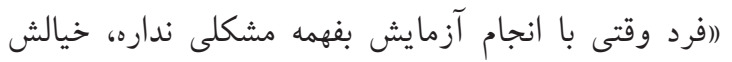

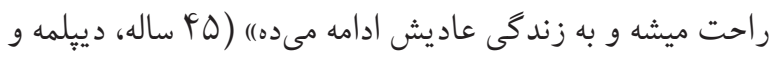

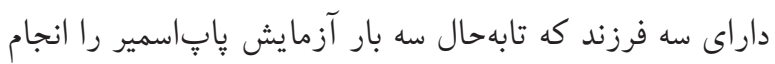
داده است).

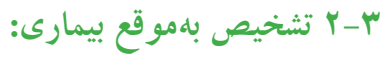
(نفع انجام پاباسمير اينه كه وقتى زود بدونى كه مريض

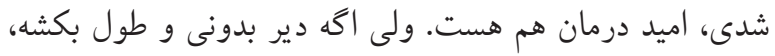
ديخه درمانش هم فايده نداره)) (W هاله، سواد ابتدايى و داراى جهار فرزند كه تابهال دو بار آزمايش ڤإ)

(با انجام آزمايش، فرد از مشكلات بدن خودش آكاه ميشه؛ و اكه مشكلى داشته باشه، زودتر به فرياد خودش مىرسه و درمانش مؤثر ميشه)) (TH ساله، سو اد ابتدايى و داراى سه فرزند كه تابه حال يكبار آزمايش ڤا״ٍاسمير را انجام داده است).

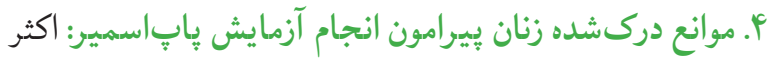

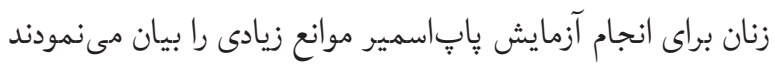

داراى جهار فرزند كه تابهحال دو بار آزمايش پاٍٍاسمير را انجام داده است). r. شدت دركشده زنان بيبرامون سرطان دهانه رحم: قريب بهاتفاق زنان بيمارى سرطان دهانه رحم يك بيمارى كشنده و بدون

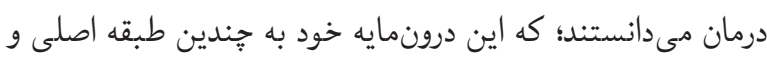
فرعى تقسيم مىشوند (جدول r).

جدول س. طبقات اصلى و فرعى درونمايه (شدت دركشده)

\begin{tabular}{|c|c|c|}
\hline طبقه اصلى & طبقه فرعى & كد آزاد \\
\hline لاعلاج بودن بيمارى & خطرناك بودن & خوب نشدن در اثر بيمارى \\
\hline برداشتن رحم مترادف با باشى خانواده & 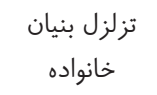 & طدم توان دادن به علت ناقصدارى و شوهردارى زن \\
\hline بار مالى & هزينه بىفايده & خرج زياد و بدون نتيجه \\
\hline
\end{tabular}

(سرطان بيمارى خطرناكى است. جون من تابهحال كسى رو

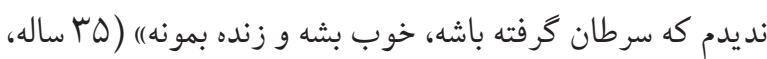

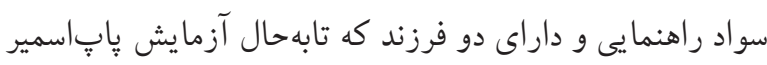

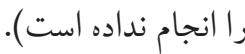

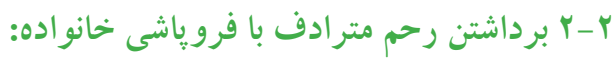
(بيمارى بديه. جون مرد وقتى بدونه زنش ناقص ميشه، فورا

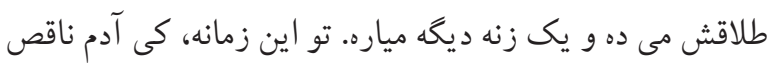

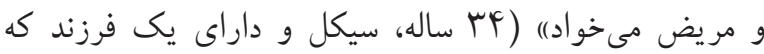
تابهال يكبار آزمايش پاٍّاسمير را انجام داده است).

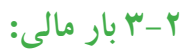
(سرطان دهانه رحم بيمارى بسيار خطرناكى است. جون

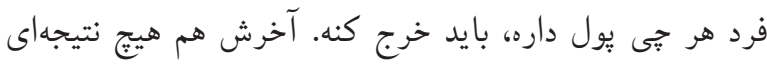
نمى كيره و مشكلات مادى براى فرد بوجود مياره و كلى بدهكار

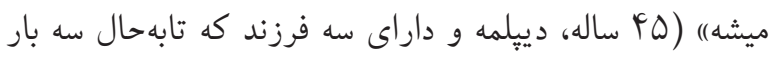
آزمايش پابٍاسمير را انجام داده است).

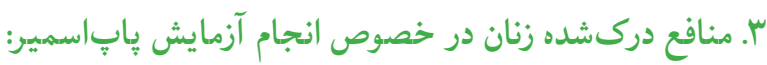

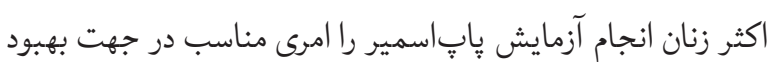



((ميگن براى آزمايش بايد كاملاً لخت بشى. من هم خجالت مى كشم و نمى تونم آزمايش بدم؛ روم نميشه)) (Y و داراى جهار فرزند كه تابهال آزمايش ياب/اسمير را انجام نداده

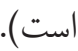

بر اساس يافتههاى اين يثوهش اكثر افراد مشاركت كننده حساسيت كمى نسبت به ابتلا به بيمارى از خود بيان مى كردند و خود را در معرض خطر ابتلا به بيمارى نمىديدند. يافتهها در

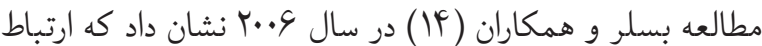
معنادارى بين پايين بودن ميزان حساسيت دركشده و مشاركت پايين زنان در انجام آزمايش پاٍٍاسمير وجود داشت. نتايج تحقيق

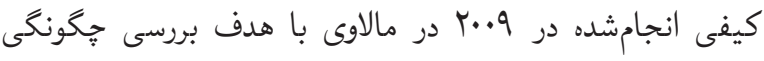
تصميم گيرى زنان جهت مراجعه براى انجام آزمايش پابٍاسمير نتايج نشان داد كه علت اصلى اقدام نكردن براى غربالخرى در

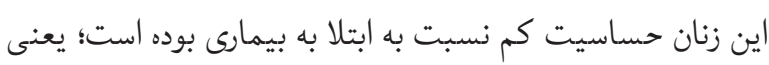
شركت كنندگان احساس نمى كردند كه ممكن است در معرض ابتلا به بيمارى قرار كيرند (10). مطالعه نشان داد زنانى كه حساسيت دركشده بيشترى در خصوص سرطان دهانه رحم دارند، نسبت به زنانى كه حساسيت كمترى داشتند، رفتارهاى غربالكرى (انجام آزمايش) بيشترى از خود نشان مىدادند (واله). يافتههاى اين يزّوهش حاكى از آن بود كه از عوامل يايينبودن حساسيت دركشده در زنان موردمطالعه باورهاى فرهنكى اشتباه و اعتقادات مذهبى نادرست بوده است. يافتههاى كريمى و همكاران(IV) نيز با يافتهاى اين يزوهش همخوانى دارد. آنها بيان كردند كه باورهاى نادرست درباره بيمارى و نسبتدادن سلامت و بيمارى به قضا و قدر موجب كم شدن ميزان حساسيت دركشده در زنان موردمطالعه بوده است. بر اساس تعريف، شدت دركشده باور انتزاعى فرد در مورد وسعت آسيبى است كه مىتواند درنتيجه ابتلاى به بيمارى يا
كه اين درونمايه خود به جندين طبقه اصلى و فرعى تقسيم مىشوند (جدول ه).

جدول ه. طبقات اصلى و فرعى درونمايه موانع دركشده)

\begin{tabular}{|c|c|c|}
\hline طبقه اصلى & طبقه فرعى & كد آزاد \\
\hline نداشتن آكاهى & ن بود دانش & نبود شناخت خاص در \\
\hline كمبود وقت & 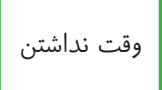 & نبود وقت به دليل \\
\hline ترس از جواب مثبت آزمايش & ترس داشتن & ترسيدن آز جواب مثبت \\
\hline خجالت از انجام آزمايش & خجالت كشيدن & خجالت از لخت شدن براى \\
\hline
\end{tabular}

(امن شناخت خاصى درباره اين آزمايش نداشتم و جيز زيادى

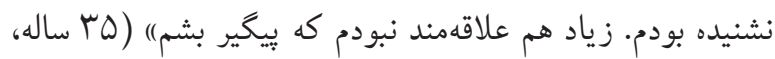

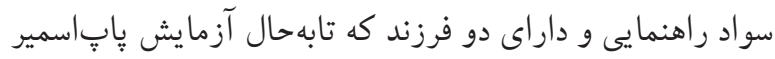

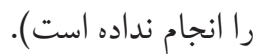
) (من نمىدونستم كه من هم بايد اين آزمايش رو انجام

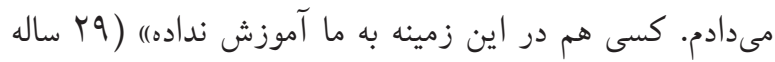

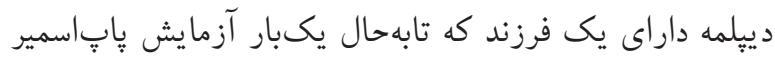

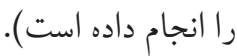

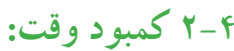
إ(من وقت ندارم. جون بنج تا فرزند دارم و وقتم كامل صرف

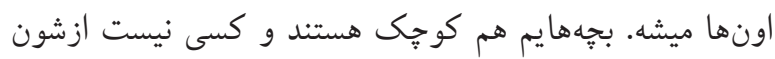

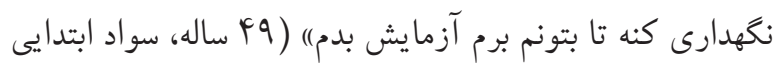

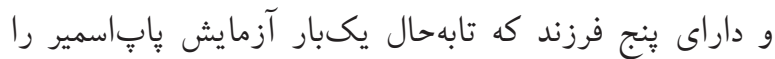

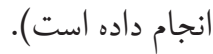

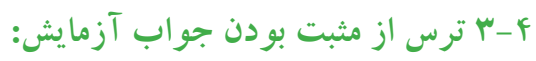
آرن از انجام آزمايش مى ترسم. جون ميكم مبادا جواب

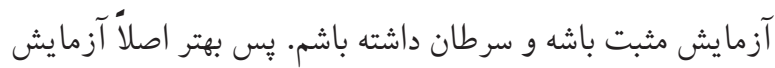

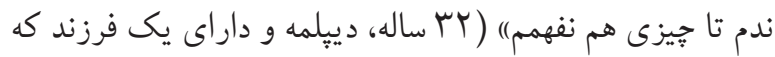
تابهال يكبار آزمايش بإِاسمير را انجام داده است). 
آزمايش و يرداخت هزينه براى انجام آن برشمردند؛ كه با يافتهاى

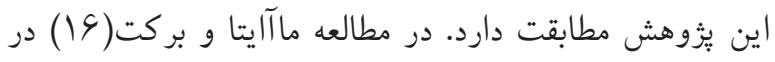

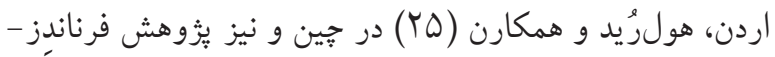

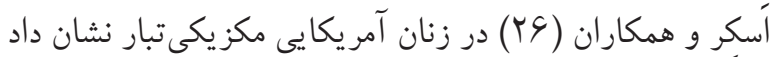

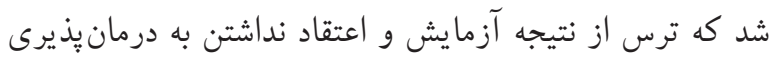

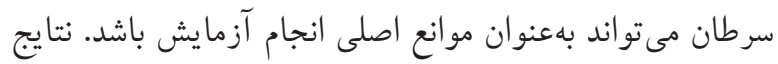

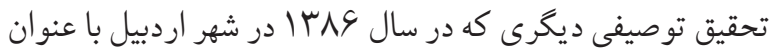

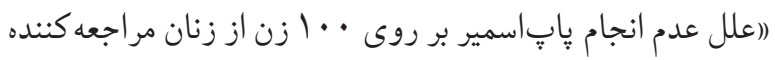

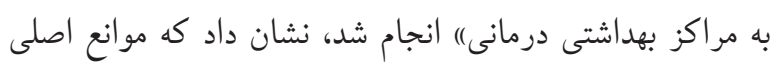

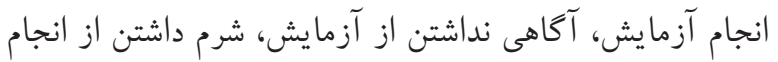

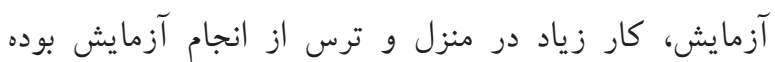

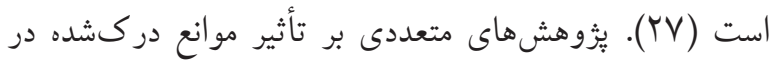
انجام رفتارهاى غربالكرى سرطان دهانه رحم تأكيددارند. نتايج يزوهشهاى انجامشده در اين زمينه نشان داد زنانى كه سطح

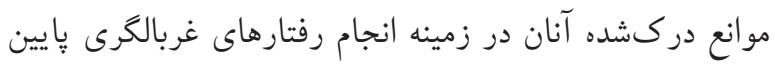

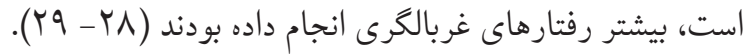

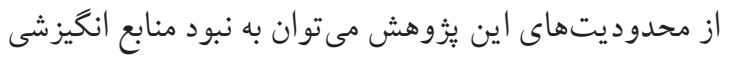

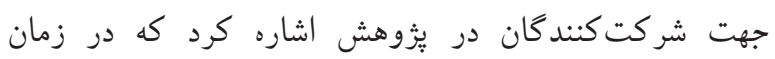

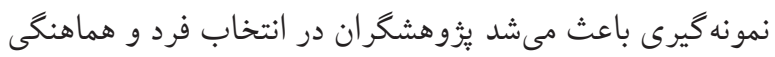
جهت انجام مصاحبهها با دشوارىهايى روبرو شوند.

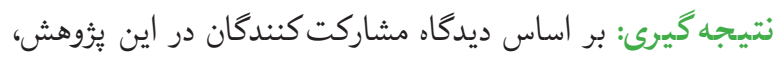
عوامل متعددى در شركت در غربالكرى و انجام آزمايش يُ برد

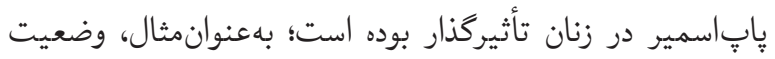
اجتماعى، اقتصادى، عوامل فرهنكى، نكُش و و اعتقادات فرد. در اين ميان از موانع انجام شركت در غربالكرى هم عواملى مشخصشدهاند: آكاهى كم، ترس، محدوديت زمانى و هزينه آنها. بر اين اساس، لازم است در تهيه و تدوين و اجراى برنامههاى

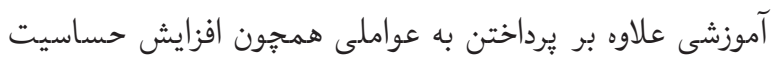

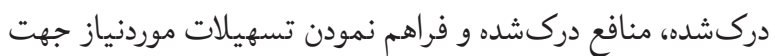

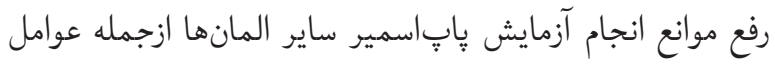

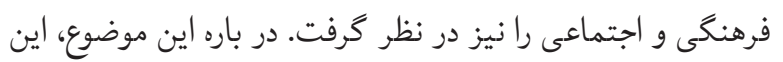

يك وضعيت زيانبار حاصل از يك رفتار خاص بديد آيد( • ().

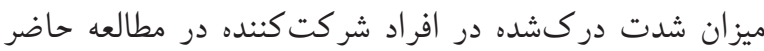
در حد زيادى بود و اكثر افراد بيمارى سرطان دهانه رحم را يك بيمارى خطرناك و كشنده توصيف مى كردند؛ كه اين با دردي

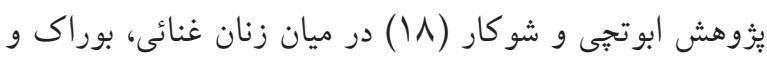

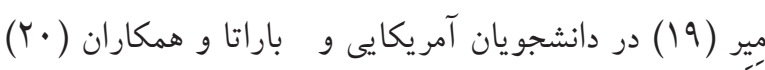
در بين زنان كانادا در خصوص بالا بودن ميزان شدت دركشده

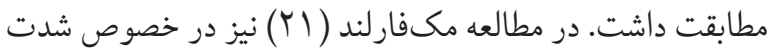
دركشده OV ٪ از نمونهها سرطان دهانه رحم را غيرقابل درمان

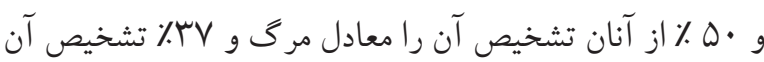
را معادل برداشتن رحم مىدانستند. در كل، اين باورهاى اشتباه

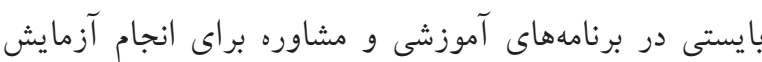

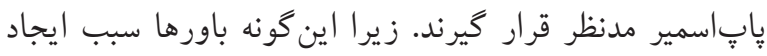

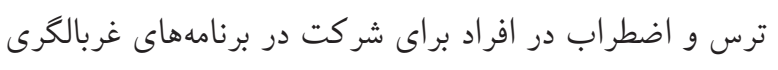
مىشود. اعتقاد به مزاياى روشهاى بيشنهادى جهت كاهش خطر

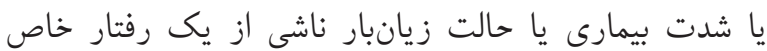

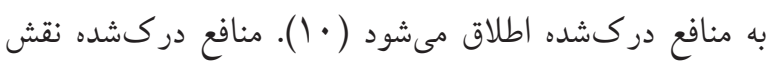
تعيين كنندهاى در ايجاد تغييرات رفتارى بخصوص رد رفتارهاى

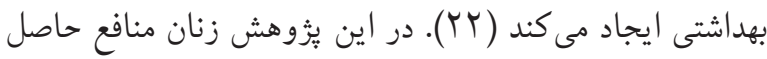

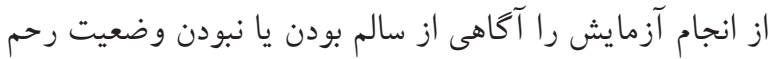

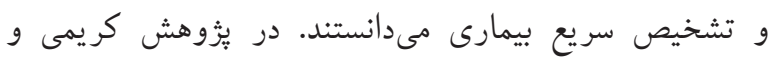

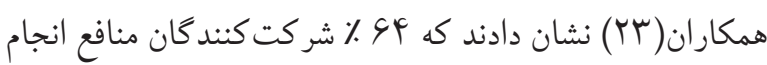
آزمايش را تشخيص زودتر و بهموقع مشكلات مىدانستند.

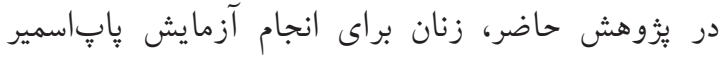

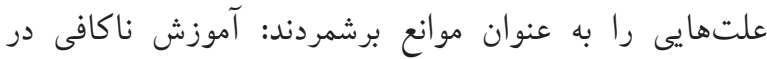

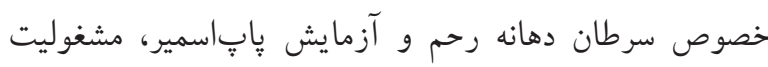

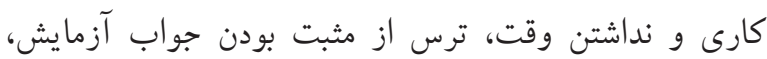

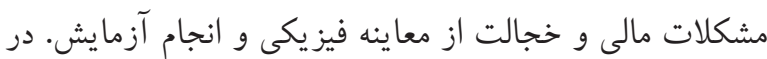

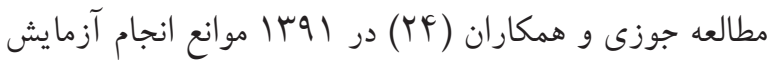

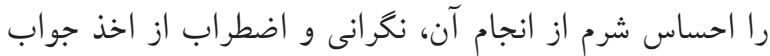




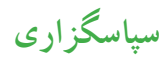

$$
\begin{aligned}
& \text { اين يثوهش بخشى از نتايج طرح تحقيقاتى با عنوان ((بررسى }
\end{aligned}
$$

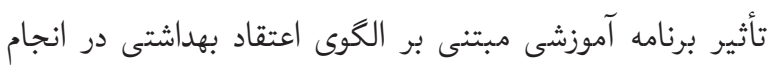

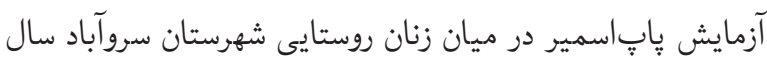

$$
\begin{aligned}
& \text { | }
\end{aligned}
$$

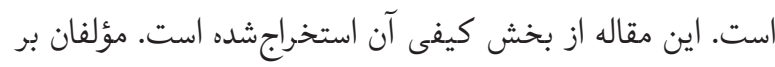

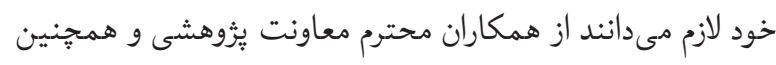

$$
\begin{aligned}
& \text { شبكه بهداشت و درمان شهرستان سروآباد تقدير و تشكر كنند. }
\end{aligned}
$$

\section{References:}

1. Su TT. Factors related to poor practice of pap smear screening among secondary school teachers in Malaysia. Asian Pacific journal of cancer prevention. 2011;12(5).

2. Bruni L, Diaz M, Castellsagué $M$, Ferrer E, Bosch FX, de Sanjosé S. Cervical human papillomavirus prevalence in 5 continents: meta-analysis of 1 million women with normal cytological findings. Journal of Infectious Diseases. 2010;202(12):1789-99.

3. Arbyn M, Castellsagué $X$, de Sanjosé $S$, Bruni L, Saraiya $M$, Bray F, et al. Worldwide burden of cervical cancer in 2008. Annals of oncology. 2011;22(12):2675-86.

4. Jemal A, Center MM, DeSantis C, Ward EM. Global patterns of cancer incidence and mortality rates and trends. Cancer Epidemiology Biomarkers \& Prevention. 2010;19(8):1893907.

5. Hoory T, Monie A, Gravitt P, Wu T-C. Molecular epidemiology of human papillomavirus. Journal of the Formosan Medical Association. 2008;107(3):198-217.

6. Näslund GK, Fredrikson M. Health behavior, knowledge and attitudes among Swedish university students. Scandinavian journal of psychology. 1993;34(3):197-211.

7. Aalam M, Mohammad AS, Aflatounian M, Azizzadeh F. Knowledge, attitude and practice of behaviors working in healthcare centers of Kerman medical university toward pap smear. 2007.

8. Coughlin SS, King J, Richards TB, Ekwueme DU. Cervical cancer screening among women in metropolitan areas of the United States by individual-level and areabased measures of socioeconomic status, 2000 to 2002. Cancer Epidemiology Biomarkers \& Prevention. 2006;15(11):2154-9.

9. Gakidou E, Nordhagen S, Obermeyer Z. Coverage of cervical cancer screening in 57 countries: low average levels and large inequalities. PLoS Med. 2008;5(6):e132.

$$
\begin{aligned}
& \text { راه كارها بيشنهاد مىشوند: توجه بيشتر مسئولين وزارت بهداشت } \\
& \text { به بحث ارتقاء سلامت زنان و تسهيل روند غربالخرى، استفاده } \\
& \text { از برنامههاى آموزشى نظريهمحور، فيلمهاى آموزشى، پيمفلت و } \\
& \text { برگزارى كلاسهاى آموزشى جهره به جهره، مشاورههاى تخصصى } \\
& \text { و سخنرانى روحانيون و افراد بانفوذ در جامعه و همجنين استفاده } \\
& \text { از الكوهاى تغير رفتارى كه آيتم و سازههاى رفتارى را بيشخوى } \\
& \text { مىنمايند ازجمله الكوى پِندر در تحقيقات آتى. }
\end{aligned}
$$

10. Vahedian-Shahroodi M, Elaheh L-m, Esmaily $H$, Tehrani $\mathrm{H}$, Hamidreza M-H. Prediction of osteoporosis preventive behaviors using the Health Belief Model. Iranian Journal of Health Education and Health Promotion. 2014;2(3):199207.

11. Center S. Unit for prevent and fight against disease. Iran: Sarvabad Health Center. 2014.

12. Haidari S, Salahshourian A, Rafii F. The relationship between social support and quality of life in cancer patients affiliated to Iran University of Medical Sciences [MSc Thesis]. Tehran, Iran: Iran University of Medical Sciences. 2006:124-5.

13. Hsieh H-F, Shannon SE. Three approaches to qualitative content analysis. Qualitative health research. 2005;15(9):1277-88.

14. Bessler $P$, Aung $M$, Jolly $P$. Factors affecting uptake of cervical cancer screening among clinic attendees in Trelawny, Jamaica. Cancer Control. 2007;14(4):396.

15. Wong L, Wong Y, Low W, Khoo E, Shuib R. Knowledge and awareness of cervical cancer and screening among Malaysian women who have never had a Pap smear: a qualitative study. Singapore medical journal. 2009;50(1):49.

16. Maaita M, Barakat M. Jordanian women's attitudes towards cervical screening and cervical cancer. Journal of obstetrics and gynaecology. 2002;22(4):421-2.

17. Karimi M, Ghofranipor F, Heidarnia A. The effect of health education based on health belief model on preventive actions of AIDS on addict in Zarandieh. Journal of Guilan University of Medical Sciences. 2009;18(70):64-73.

18. Abotchie PN, Shokar NK. Cervical cancer screening among college students in ghana: knowledge and health beliefs. International journal of gynecological cancer: official journal of the International Gynecological Cancer Society. 2009;19(3):412. 
19. Burak LJ, Meyer M. Using the Health Belief Model to examine and predict college women's cervical cancer screening beliefs and behavior. Health Care for Women International. 1997;18(3):251-62.

20. Barata PC, Mai V, Howlett R, Gagliardi AR, Stewart DE. Discussions about self-obtained samples for HPV testing as an alternative for cervical cancer prevention. Journal of Psychosomatic Obstetrics \& Gynecology. 2008;29(4):2517.

21. McFarland DM. Cervical cancer and Pap smear screening in Botswana: knowledge and perceptions. International Nursing Review. 2003;50(3):167-75.

22. Sullivan KA, White KM, Young RM, Chang A, Roos C, Scott C. Predictors of intention to reduce stroke risk among people at risk of stroke: An application of an extended health belief model. Rehabilitation Psychology. 2008;53(4):505.

23. Karimi M, Shamsi M, Arban M. Measurement constructs and factors affecting health belief model for Pap smear test for women in urban centers of zarandieh. J Qom Univ Med Sci. 2012;6(3):52-9.

24. Jowzi F, Hashemifard T, Morowatisharifabad M, Bashir Z. Factors Associated with Pap Smear Screening Test among
Women Aged 15-49 based on Protection Motivation Theory. Journal of hayat. 2013;19(1):29-40.

25. Holroyd E, Twinn S, Adab P. Socio cultural influences on chinese womenss attendance for cervical screening. Journal of advanced nursing. 2004;46(1):42-52.

26. Fernández Esquer M, Espinoza P, Ramirez A, McAlister A. Repeated Pap smear screening among Mexican-American women. Health Education Research. 2003;18(4):477-87. https://doi.org/10.1093/her/cyf037

27. Mostafazadeh F, Mashofi M, Haji aqamohammadi P. Assessment of Factors related to poor practice of pap smear from view of women in health centers of Ardabil during 2006 to 2007. Journal of Health And Care. 2008;10(3):230-2235.

28. Jirojwong S, Maclennan R, Manderson L. Health beliefs and Pap smears among Thai women in Brisbane, Australia. Asia-Pacific Journal of Public Health. 2001;13(1):20-3.

29. Lee MC. Knowledge, barriers, and motivators related to cervical cancer screening among Korean-American women: A focus group approach. Cancer nursing. 2000;23(3):168-75.

If 